UDC: 821.134.2.09-2

DOI: https://doi.org/10.18485/beoiber.2017.1.9

\author{
Eszter Katona' \\ Universidad de Szeged \\ Hungría
}

\title{
EL TEATRO DE LA MEMORIA: CINCO DRAMAS CONTRA EL OLVIDO
}

\begin{abstract}
Resumen
El teatro de la memoria es una tendencia característica en el drama español actual. Nuestro artículo, después de una introducción al tema, quisiera ofrecer un breve análisis de cinco obras que tienen la función de llenar huecos en la tela de la memoria. La base de nuestra selección ha sido cronológica: los cinco dramas -según las fechas desde la cual los personajes rememoran los acontecimientos y las consecuencias de la guerra civil española - tienen cinco perspectivas y abarcan aproximadamente seis décadas en la línea del tiempo de la memoria. Todos hacen dirigir la mirada del lector / espectador de hoy hacia cinco momentos de la historia - La piedra oscura a 1937, El convoy de los 927 y El triángulo azul a los años 1940-1945 recordados desde 1965, El jardín quemado y Pies descalzos bajo la luna de agosto a los últimos momentos de la guerra civil evocados desde los últimos años 70 y finales de la década de los 90 respectivamente- $y$ sacan a la luz de la oscuridad del olvido las memorias silenciadas.

Palabras clave: Teatro de la memoria, Joan Cavallé, Alberto Conejero, Mariano Llorente, Juan Mayorga, Laila Ripoll.
\end{abstract}

\section{THE THEATRE OF MEMORY: FIVE PLAYS AGAINST OBLIVION}

\begin{abstract}
The theatre of memory is a significant trend in today's Spanish drama. The article, after an introduction to the subject, offers a brief analysis of five plays that have the function of filling the holes in the fabric of memory. The principle of our selection was chronological: the five plays - in order of the moments from which the characters recall the events and consequences of the Spanish Civil War - have five perspectives and comprise approximately six decades on the timeline of memory. All the five plays draw the present-day readers' / spectators' attention to five moments in history - The Dark Stone to 1937, The 927 Convoy and The Blue Triangle to the years 1940-1945 remembered from 1965, The Burned Garden and Barefoot under an August Moon to the last moments of the civil war evoked from the late 1970s and the late 1990s respectively - and bring the silenced memories to light from the darkness of oblivion.

Key words: The Theater of Memory, Joan Cavallé, Alberto Conejero, Mariano Llorente, Juan Mayorga, Laila Ripoll.

\footnotetext{
1 katonaeszter@gmail.com
} 
"Sin memoria no hay mañana, sin memoria no hay avenir."

(Ripoll 2013: 229)

\section{Introducción}

Durante las cuatro décadas de la dictadura franquista (1939-1975) la censura del régimen determinó las estrechas coordenadas de toda la producción cultural -sea literaria, dramática o cinematográfica- en España. Las directrices del régimen tabuizaron muchos temas, así la guerra civil (1936-1939) evocada desde el punto de vista de los vencidos o la crítica del régimen imperante fueron motivos intocables en la literatura, en el teatro y en el cine.

Después de la muerte de Franco, la transición democrática se realizó de manera pacífica gracias a una política de consenso porque, a pesar de las divergencias entre opiniones, los españoles estaban de acuerdo en una cuestión primordial: el consenso era indispensable para evitar un nuevo derramamiento de sangre. La política de la memoria adoptada en los años de la transición dejó de lado conscientemente temas tan espinosos como la culpa y la responsabilidad y abogó por el consenso y la reconciliación del país (García Martínez 2016: 18). La garantía de este fue el llamado "pacto de silencio" respetado por todos los personajes de la vida política española, o sea, entró en vigor la ley de "no hablar del pasado", que conllevó la desmemoria de la sociedad española.

Este "gran tabú colectivo de la transición" (Colmeiro 2001: 155) aplazó encarar el pasado, pero la amnesia colectiva resultó insostenible ya que sin memoria era imposible construir el futuro. Según Manuela Fox, uen la sociedad española, la memoria negada sigue presentándose [...] de manera casi patológica, como en un paciente traumatizado, cuyo recuerdo latente de lo que ha ocurrido lo persigue y atormenta" (2012: 110). Jurídicamente, la Ley de la Memoria Histórica, aprobada en 2007, puso fin a esta "cancelación del pasado" e hizo posible las investigaciones en los archivos, las excavaciones de las fosas comunes, la búsqueda de los responsables y la rehabilitación de las víctimas y sus familiares. La ley -discutida por muchos- devolvió a los españoles el derecho a la memoria, un deseo oprimido en la sociedad durante tres décadas de democracia.

Sin embargo, si examinamos las artes, podemos notar que "el pacto de silencio" generó un fenómeno contrario. La literatura, el teatro y el cine no tuvieron que esperar hasta la fecha de la ley mencionada porque las artes, sin la censura, rompieron mucho antes el obligado silencio. La narrativa reaccionó inmediatamente a "la amnesia forzada" engendrando más de tres mil obras de creación literaria, según los datos de Maryse 
Bertrand de Muñoz (1986: 358) -en la década de los 80-, pero esta bibliografía no ha dejado de ampliarse hasta nuestros días².

El teatro igualmente se negó al olvido y, en vez del silencio, optó por "el pacto de la memoria" ${ }^{3}$. Durante décadas el teatro de la memoria era confundido con el teatro histórico y, aunque María Teresa Cattaneo ya en 1989 expresó su opinión según la cual "las muchas piezas [...] que recuperan el pasado reciente del final de la guerra y de la dictadura [...] no encajan [...] en la definición del teatro histórico" (1989: 12), hubo que esperar hasta el exhaustivo ensayo de Wilfried Floeck (2006) para que las características específicas del teatro de la memoria fueran aclaradas y sintetizadas. Este cambio de paradigma, pasando del modelo del teatro histórico de raíces realistas a una forma de teatro de la memoria fue una reacción normal a la política del olvido promovida durante la transición. Este género nuevo, nacido en la década de los $80-y$ cuyo florecimiento sigue aún en nuestros días-, es un teatro comprometido en sentido social, pero con "una tendencia a la despolitización" ${ }^{4}$ y sin la pretensión de realizar una reconstrucción fiel y documentada de los hechos históricos. Son unas miradas individuales sobre el pasado reciente que estuvieron ocultadas durante décadas pero ahora han ocupado no solo las páginas de las novelas y los libros memorialísticos sino también la escena teatral. Anabel García Martínez, en su libro recién publicado, menciona más de setenta obras sobre la guerra civil y la dictadura (2016: 12). Los datos de Alison Guzmán son diferentes de los de la filóloga antes mencionada: ella, en su tesis doctoral, registra, en total, 149 obras de teatro sobre la guerra civil española, de las cuales 63 nacieron entre 1939 y 1969, y 86 entre 1970 y 2006 (2012: 23-24)5. Desde el punto de vista del objetivo del presente artículo no nos importa el número exacto de obras ${ }^{6}$, es más interesante llamar la atención sobre este verdadero "memory boom" (Huyssen 1995) en el teatro. Además, para subrayar la actualidad del tema, nuestra selección abarca el periodo posterior a la

${ }^{2}$ Claro está que el tema se ha convertido en un negocio editorial muy rentable. "Se publican muchas novelas de la Guerra Civil porque la Guerra Civil vende" - opina David Becerra Mayor (Entrevista a Becerra, 8 de abril de 2015), autor del libro La Guerra Civil como moda literaria (Madrid, Clave Intelectual, 2015).

3 Repasando las piezas teatrales de la transición podemos constatar que la memoria de la guerra civil española estuvo muy viva en estos años con un amplio abanico de estrategias dramatúrgicas. Para citar solo algunos ejemplos de los años 70-90: Las bicicletas son para el verano (1977) de Fernando Fernán Gómez, Noche de guerra en el Museo del Prado (1978) de Rafael Alberti, Gernika: un grito, 1937 (1995) de lgnacio Amnestoy, Misión al pueblo desierto (1999) de Antonio Buero Vallejo. Especial mención merece iAy, Carmela! (1986) obra emblemática de José Sanchís Sinisterra al servicio de la reivindicación de la memoria histórica.

4 Junto a la despolitización, Floeck destaca las características siguientes: "una tendencia a [...] la plasmación multiperspectivista y la subjetivización de la perspectiva, a la fragmentación y a la estructura abierta, que exige la participación activa del lector o del espectador" (2006: 205).

${ }^{5}$ Al final de la disertación se encuentra la lista de las obras estudiadas (Guzmán 2012: 589-592).

${ }^{6}$ Por la cronología de Alison Guzmán -que termina en 2006-cuatro de los cinco dramas analizados en adelante no pertenecen a los textos examinados por la autora. 
cronología de Guzmán7. Aunque el estudio de la narrativa que toca el tema del período bélico y dictatorial, sin duda alguna, atrae aún más la atención de los investigadores, el análisis de este fenómeno teatral y el del corpus perteneciente a este género dramático reciben cada vez mayor atención ${ }^{8}$.

\section{Cinco dramas, cinco momentos de la memoria}

Los dramaturgos del teatro español de hoy pertenecen a la generación de los nietos -en su mayoría, no tienen experiencias directas de la dictadura-, son los representantes de la llamada postmemory (Hirsch, 1997) que asumen voluntariamente la tarea de curar la desmemoria de los españoles. Hemos elegido cinco piezas teatrales de cinco autores, nacidos entre 1958 y 1978, de los cuales cuatro nacieron aún en el franquismo -Joan Cavallé en 1958, Laila Ripoll en 1964, Mariano Llorente y Juan Mayorga en 1965-, y sin embargo, conocen la guerra y los años más duros de la dictadura solo de las narraciones de sus padres y abuelos. Uno de los dramaturgos, Alberto Conejero (1978), pertenece a la generación nacida durante la transición.

Manuela Fox afirma con razón que a partir de la década de los ochenta hasta nuestros días, los dramaturgos ofrecen "una valiosa contribución para llenar los huecos que la historiografía franquista y la amnesia generalizada de la transición habían excavado en la memoria colectiva española" (2012: 111). Las cinco obras elegidas para nuestro análisis tienen esta función de llenar huecos en la tela de la memoria. La base de nuestra selección ha sido cronológica: los cinco dramas -según la fecha desde la cual los personajes rememoran sobre los acontecimientos y las consecuencias de la guerra civil española- tienen cinco perspectivas y abarcan aproximadamente seis décadas en la línea del tiempo de la memoria9: desde 1937, fecha de la acción dramática de La piedra oscura, hasta 1997, tiempo de los acontecimientos de Pies descalzos bajo la luna de agosto.

La piedra oscura de Alberto Conejero dirige nuestra mirada a 1937, mientras que El convoy de los 927 de Laila Ripoll y El triángulo azul de Mariano Llorente y Laila Ripoll rememoran los dolorosos recuerdos de los deportados españoles a Mauthausen. El jardín quemado de Juan Mayorga evoca una historia olvidada de la guerra civil ya desde la perspectiva de la transición, a finales de los años 70 y, por último, Pies descalzos bajo la luna de agosto de Joan Cavallé busca repuestas a las crueldades del pasado ya en la democracia, a finales de la década de los 90.

${ }^{7}$ Con la única excepción de la obra de Juan Mayorga, escrita en 1996.

${ }^{8}$ Hay que destacar las investigaciones del ya mencionado Wilfried Floeck, las de César Oliva, María Francisca Vilches de Frutos, José Romera Castillo, Francisco Gutiérrez Carbajo, Francisco Ernesto Puertas, Eduardo Pérez Rasilla, José Paulino Ayuso, Manuela Fox, Alison Guzmán y Anabel García Martínez, entre muchos otros.

${ }^{9}$ Nuestra selección fue motivada también por la traducción literaria de las cinco obras al húngaro (la edición está en proceso).

BEOIBERÍSTICA Vol. I / Número 1 (2017) | 133-146 
La elección del tema de La piedra oscura (publicado en 2013, estrenado en 2015) es relevante y actual, por un lado, por el octogésimo aniversario en 2016 de la muerte de Federico García Lorca y, por otro, por las polémicas despertadas acerca de la exhumación de la fosa del gran poeta. Además, la estrecha intertextualidad del drama con los textos lorquianos hace muy especial esta pieza. Sin embargo, el protagonista de la obra no es Federico García Lorca, sino Rafael Rodríguez Rapún, el secretario de La Barraca, último gran amor del poeta. Una celda de un hospital militar constituye el espacio dramático y las últimas horas de Rapún, antes de su fusilamiento, dan el marco temporal de la obra. Dos personajes, Rapún, el prisionero y Sebastián, su custodia desarrollan un extenso diálogo a lo largo de los ocho fragmentos indicados con números romanos y titulados -o algunos de ellos introducidos- con citas lorquianas. De este diálogo, gracias a los fragmentos de memoria de Rafael, se dibuja la complicada relación amorosa entre el poeta y el estudiante de ingeniería de minas. Fotografías, cartas, recuerdos de la familia y de los amigos de Rapún y textos de García Lorca ayudaban al dramaturgo en la reconstrucción del pasado, aunque el encuentro entre Rapún y Sebastián nunca se produjo, es una ficción ${ }^{10}$. A propósito de la fusión de la realidad y la ficción es interesante citar las palabras de Alberto Conejero, refiriéndose a Juan Mayorga: “Insisto, [...] siguiendo a Mayorga, el historiador se ocupa de lo que ha sucedido pero el dramaturgo puede ocuparse de lo que podría haber sucedido" (Conejero 2015b: 9). Junto al carácter documental" ${ }^{11}$ ficcional, tenemos que destacar también el profundo lirismo de la obra, gracias al juego con los fragmentos lorquianos ${ }^{12}$ introducidos en muchos puntos en el texto del dramaturgo, premiado por esta obra con cinco Premios Max.

Con este drama Conejero hace salir a Rodríguez Rapún de la sombra de Federico y de los pocos párrafos dedicados a él en las biografías de Lorca. Sin embargo, no solo conocemos los destinos individuales de los dos jóvenes que comparten unas horas antes

10 Conejero mismo nos adelanta esta fusión entre ficción y documentación en la Nota de autor: "el encuentro del que se ocupa mi obra es ficción. Sin embargo, el resto de informaciones, datos, nombres, sucesos, etc. son el resultado de la investigación que desarrollé durante los últimos años" (Conejero 2015c: 17).

${ }^{11}$ Alusiones a acontecimientos histórico-políticos (el asesinado de Calvo Sotelo), a lugares reales donde se desarrollaba el conflicto armado (Bárcenas, Matamorosa, Santander), a lugares conocidos de Madrid (Casa del Campo, Puerta del Sol), a personajes reales (Modesto Higueras, Martínez Nadal o los padres y los hermanos de Rapún), a momentos y lugares importantes en la vida de Federico (Granada, Huerta de San Vicente y su viaje a Argentina), al itinerario de La Barraca (Santander, San Sebastián).

12 En el texto abundan las citas del ciclo de Sonetos del amor oscuro (El poeta pide a su amor que le escriba, Llagas de amor, Noche del amor insomne, El amor duerme en el pecho del poeta), hay fragmentos del Libro de poemas (La sombra de mi alma), del tomo Primeras canciones (Adán), del Diván del Tamarit, (Casida de los ramos), del libro Poeta en Nueva York (Nocturno del hueco, Asesinato) y del poema Llanto por lgnacio Sánchez Mejías. Los fragmentos en prosa son menos, pero igualmente de mucho valor: una carta de Lorca a Rapún y un pasaje de la Charla sobre teatro, ars poética teatral de García Lorca. El mismo título de la obra, La piedra oscura, es una alusión a una pieza proyectada pero no realizada de García Lorca sobre el tema de la homosexualidad. 
de la muerte de uno de ellos, sino que tenemos una mirada más amplia sobre la historia de España de los años de la guerra. Rafael y Sebastián simbolizan el país dividido, los dos bandos opuestos en la guerra y, en sus razonamientos, presentan la ideología republicana (Rafael) y la del bando nacional (Sebastián). A pesar de que están en lados enemigos, la tensión entre los dos hombres disminuye cada vez más según se va acercando el momento del fusilamiento, y el joven Sebastián promete a su preso que cumplirá el último deseo de este: intenta salvar las obras de García Lorca guardadas en secreto para las generaciones posteriores.

En el diálogo entre Rapún y Sebastián, conducido con maestría, se perfila toda la tragedia de la sociedad española, y el mensaje de la obra -opina lan Gibson (2015) - «es necesario en una España donde, vergonzosamente, todavía yacen en cunetas más de 100.000 víctimas del fascismo, entre ellos el desaparecido más célebre de todos" ${ }^{13}$. Con $L a$ piedra oscura el dramaturgo hace "una indagación sobre los que quedaron en los márgenes de la foto oficial de la Historia", sobre la generación de los padres y abuelos, sobre aquellos que fueron casi devorados por el tiempo y el olvido.

Laila Ripoll, como "nieta de exiliados" (Henríquez 2005: 118), igualmente sentía una deuda con el pasado al escribir su obra El convoy de los 927 (en 2007, estrenada en $2008^{14}$ ) sobre la memoria de los exiliados republicanos y los deportados españoles a los campos de Hitler. La historia real del convoy de los 927 españoles que partió el 20 de agosto de 1940 del campo de concentración de Angulema con destino a Mauthausen da la base documental del drama ${ }^{15}$. En la estación austríaca salieron del convoy 470 hombres -las mujeres y los niños fueron reenviados a España-, del primer tren que llegó a la fábrica de muerte antes de que empezara el exterminio sistemático de los judíos. El motivo central del drama es el viaje de 18 días en tren, el largo viaje del que escribió también su famoso testimonio Jorge Semprún, aunque con destino a Buchenwald. Ripoll centra nuestra atención en la conmovedora historia de una familia de cinco miembros: al terminar el viaje, el padre y el hijo mayor, separados de los otros tres, quedan en Mauthausen, mientras que la madre con los otros dos hijos -Ángel y Lolita- vuelven a España. El padre que llega al campo ya enfermo muere casi en seguida, pero el adolescente Ramiro sobrevive el infierno. Al regresar a su patria logra encontrar a su familia, pero el horror del pasado queda imborrable en su memoria.

13 Es bien conocida la opinión de la familia García Lorca que rechaza rotundamente la exhumación. A pesar de eso, desde la aprobación de la Ley de la Memoria Histórica (2007) hubo tres excavaciones oficiales en la zona -las últimas, en septiembre de 2016, terminaron otra vez sin resultados- donde se suponen los restos del poeta granadino. El debate acerca de la búsqueda de la fosa y la exhumación de los huesos del poeta más célebre del siglo XX expresa bien la dicotomía entre la memoria y el olvido, dos políticas opuestas e irreconciliables hasta hoy día.

14 Originalmente, la obra fue escrita para teatro radiofónico, pero se puso en escena por primera vez en 2008, en la adaptación y dirección de Boni Ortiz.

15 Laila Ripoll utilizó documentos históricos para escribir su obra, entre ellos el libro El convoy de los 927 de Montse Armengou y Ricardo Belis y la película documental homónima. 
La historia se anima en la escena gracias a las rememoraciones de Ángel ya adulto que funciona en el presente como narrador, pero en el pasado aparece como hijo pequeño, es decir, Ángel niño. Los cambios entre el punto de vista adulto -a una distancia de sesenta años de los acontecimientos- y el infantil, es decir, el entrelazamiento constante entre el presente y el pasado da un peculiar ritmo a la pieza. Las palabras de Ángel adulto, al final de la obra, - -Hace ya sesenta años y todavía, a día de hoy, ni un triste monolito en nuestro país recuerda a los miles de españoles que dieron su vida por la libertad en el campo de concentración de Mauthausen" (Ripoll 2007: 26) - reflejan la opinión de Laila Ripoll, con el mismo mensaje que nos da también Alberto Conejero: la memoria es una deuda con nuestro futuro. La obra de la dramaturga madrileña erige un monumento duradero contra la amnesia colectiva.

El campo de Mauthausen es también la escena del drama El triángulo azul (2014) de Mariano Llorente y Laila Ripoll, galardonado con el Premio Nacional de Literatura Dramática en 2015. La relación entre las dos piezas es muy estrecha, ya que esta última evoca los cinco años pasados en el campo de concentración, aquel periodo que formó un hiato para olvidar en el drama anterior. Semejantemente a la obra sobre el convoy español, El triángulo azul se construye también de rememoraciones, pero esta vez no es una víctima española quien evoca los dolorosos recuerdos sino que es Paul Ricken, un fotógrafo alemán. La acción dramática empieza en 1965, en Colonia, en la casa de Ricken $\mathrm{y}$, a través del monólogo de un hombre roto, se nos dibuja una persona que se siente culpable por haber participado en aquella "orgía de sangre". Aunque él mismo no mató a nadie, con su Leica documentó toda la crueldad de la fábrica de muerte nazi. De las brumas de la memoria de Ricken se animan en la escena los episodios brutales de los años 1940-1945, cuando los siete mil españoles rojos pasaron por Mauthausen. De su rememoración salen, como fantasmas, los presos españoles (Paco, Toni, Jacinto) y sus verdugos alemanes. La primera impresión del campo es irónicamente alegre, gracias al ritmo del pasodoble El triángulo azul que explica con humor negro el significado de los diferentes colores de los distintivos que llevaban los presos: los Rotspanier recibieron el azul, el color de los apátridas, "de los que nadie quería, a los que todos abandonaron" (Llorente y Ripoll 2014: 24). Ricken, como fotógrafo alemán, tuvo que inmortalizar cada momento en la fábrica de la muerte: en sus fotografías eternizó a los presos, a los SS, las celebraciones, los suicidios, las ejecuciones y las visitas de las autoridades alemanas. Con lo ingente del horror el trabajo era también inmenso, así, para revelar y clasificar las fotos, colocaron junto a Ricken a dos españoles, Toni y Paco.

Semejantemente al drama El convoy de los 927, los autores de El triángulo azul se inspiraron en documentos e historias de personajes reales. En las figuras de Toni y Paco podemos reconocer a Antonio García Alonso, un fotógrafo tortosino, y a Francisco Boix, un catalán de la misma profesión, el único de nacionalidad española que después de sobrevivir a Mauthausen participó como testigo en el proceso de Núremberg y declaró contra importantes miembros del gobierno nazi. Boix consiguió sacar del campo los 
negativos de dos mil fotos que, posteriormente, servirían de prueba acusatoria en el juicio. Como García Alonso y Boix en la vida, en la obra los ayudantes españoles de Ricken quieren hacer salir los documentos del campo para que todo el mundo conozca esta historia infame. El fotógrafo nazi era un hombre real con el mismo nombre (Paul Ricken) como también el personaje del SS Brettmeier se basa en la figura real del Obersturmführer Georg Bachmayer. Hay que mencionar también a otro grupo de figuras reales que no aparecen en la lista de dramatis personae de la obra, sin embargo, en los diálogos y en las acotaciones sí que se evocan sus existencias: se menciona a Heinrich Himmler, Ernst Kaltenbrunner, August Eigruber, Franz Ziereis, Karl Schulz, el arquitecto Albert Speer o el médico Eduard Krebsbach.

A pesar del fondo histórico del drama, Llorente y Ripoll no siguen la tradición del teatro realista, ya que en la escena sería imposible hablar en tono realista y naturalista sobre el crematorio, la alambrada electrificada o los deportados despedazados por los perros. Poner en escena la crueldad del holocausto plantea un dilema moral y estético ante los dramaturgos, y Ripoll y Llorente han encontrado una respuesta posible. Su obra es fiel a los acontecimientos y a los hechos históricos pero su estilo se aleja del realismo y nos sorprende con una mezcla de lo grotesco, lo esperpéntico valleinclaniano, el vodevil y el humor negro. La danza macabra y la pesadilla en delirio de Toni nos evocan tanto las pinturas de El Bosco como las de Goya.

La pieza abunda en partes musicales cuyas melodías, ritmos alegres (pasodoble, chotis, polka) y textos grotescos podrían rebajar la tensión, sin embargo, el choque entre el contenido (narran el horror del crematorio, la cámara de gas, las torturas, los sufrimientos y el suicidio) y la forma (ritmo y melodía) tienen un efecto inquietante sobre el espectador ${ }^{16}$ / lector. Con este método los autores han logrado intensificar aún más el mensaje de la obra.

La siguiente obra de nuestra selección, El jardín quemado (1996) de Juan Mayorga coloca el punto de donde miramos hacia atrás, ya en los primeros años de la transición española. La pieza está estructurada en cinco fragmentos, un prólogo y un epílogo -que forman un marco- y su acción dramática nos sitúa "en España, a finales de los años setenta" (Mayorga 2014: 149). Benet, el joven psiquiatra llega a una isla indeterminada ${ }^{17}$ con el objetivo de descifrar el enigma de San Miguel, el del jardín quemado del supuesto manicomio y encontrar la verdad respondiendo a la pregunta: "iqué sucedió en San Miguel durante los años de la guerra civil?" Es decir: abrir una herida del pasado para encontrar la verdad. Para averiguarla, Benet empieza un interrogatorio, entrevistando a los internos que viven en sus propios mundos cerrados. Todos los pacientes del centro,

16 Aquí considero destacar el efecto de la puesta en escena que, en este caso, añade mucho al texto dramático. La autora del presente artículo vio el estreno del drama en la primavera de 2015, en el Teatro Valle-Inclán de Madrid.

17 Aunque José Monleón (2004: 25) opina que se trata de Menorca y la ocupación de Menorca por el ejército nacional franquista. El hecho de que Mayorga no nombra la isla puede fortalecer la sensación de la generalización: lo que sucedió allí, pudo suceder también en muchos otros lugares. 
para sublimar el dolor y para sobrevivir, se han inventado nuevas identidades. Es decir, como afirma Aznar Soler, "cultivan el olvido para aliviar el dolor de la memoria" y eligen la imaginación, la locura o la ficción como forma de evasión de la realidad circundante, la única forma de supervivencia (2006: 482). La amnesia radical, clave para soportar seguir viviendo, transforma la memoria de los internos en cenizas, semejantemente al jardín quemado. Los internos son unos náufragos de la guerra civil que padecen su "conciencia machacada de sangre" (Aznar Soler 2006: 482) y para no confrontarse continuamente con el dolor de la memoria, prefieren quedarse en San Miguel, que es "el paraíso del olvido [...], el reino de la memoria calcinada y de la anestesia del dolor" (Aznar Soler 2006: 483), metáfora de toda la política del olvido de la transición española.

Benet llega con sus propios prejuicios y formula su verdad sobre los hechos históricos responsabilizando al doctor Garay, pero este también tiene su versión sobre la verdad que no coincide con la del joven psiquiatra. ¿Cuál es la verdad? ¿La versión de Benet, según la cual los soldados franquistas fusilaron a Blas Ferrater y sus once compañeros? ¿O la de Garay que sugiere que en vez de los doce republicanos entregó a los soldados a doce víctimas inocentes? Garay se absuelve del crimen responsabilizando a sus propios muchachos porque, como dice: "Fueron ellos, los muchachos, los que encontraron una solución. Ellos mismos escogieron a los doce" (Mayorga 2014: 180) ${ }^{18}$.

Gracias a la maestría dramatúrgica de Mayorga no solo Benet busca las respuestas a unas preguntas inquietantes, sino el lector / espectador también quiere averiguar la verdad y toma posición activa en este juego dramático. Mayorga revela el enigma progresivamente: al comienzo Benet aparece como un luchador de la verdad que, basándose en las fichas del archivo, quiere denunciar el crimen de Garay, acusando al doctor con la muerte de doce intelectuales republicanos. Pero la narración que realiza Garay de los sucesos de la primavera de 1939 descubre otra verdad y, paralelamente, se desmitifica el supuesto heroísmo de Blas Ferrater. La narración del doctor nos revela que el poeta republicano no era un héroe sino un superviviente indigno de la guerra que, para salvar su propia vida, no dudó en sacrificar a doce víctimas inocentes. La verdad de Benet, con este giro inesperado, se reduce a cenizas: el poeta republicano no fue una víctima sino un verdugo. Las ideas de los dos protagonistas, Benet y Garay expresan los dos diferentes discursos sobre la guerra civil y la dictadura. Benet representa la obligación de la memoria a toda costa mientras que Garay opta por el olvido, por el no remover el pasado. El desenlace final nos sugiere que la opinión de Garay sale con éxito de esta disputa, y Benet, incapaz de averiguar toda la verdad, deja vencido la isla.

18 Es interesante notar que la doble perspectiva sobre la verdad se refleja también en el vocabulario de los dos hombres. Garay llama al lugar de fuera del centro jardín, mientras que Benet habla de un patio. Igualmente usan palabras diferentes al referirse a los habitantes del centro que, según Benet, son enfermos, internos, presos y víctimas, mientras que Garay les llama ángeles, niños y muchachos. 
Es metafórica la fosa del jardín ${ }^{19}$ con los huesos de las doce víctimas anónimas, doce muertos sin rostros, doce nombres olvidados de la historia. El tema de las fosas comunes constituye también el motivo central del drama Pies descalzos bajo la luna de agosto (2009) de Joan Cavallé20, obra galardonada en 2010 con el Premi Crítica Serra d'Or de Teatre y el Premi 14 d'Abril de Teatre. Otra conexión entre los dos dramas es que tanto Juan Mayorga como Joan Cavallé buscan las respuestas a las preguntas que plantean sus protagonistas, Benet ( $E l$ jardín quemado) y El hombre de las preguntas (Pies descalzos...): ¿Es posible reconstruir el pasado y averiguar la verdad? ¿Es posible la memoria por obligación? ¿Puede la memoria vencer sobre el olvido?

La acción dramática de la obra de Cavallé se desarrolla sesenta años después del fin de la guerra, o sea, ya en plena democracia, en un pequeño pueblo sin nombre donde los arqueólogos, en vez de restos prehistóricos, encuentran huesos humanos acompañados de casquillos de bala. La expectación que causa la aparición repentina de los restos de cinco cuerpos genera la investigación del Hombre de las preguntas, un periodista-historiador que intenta averiguar quiénes eran aquellas personas, cómo murieron y por qué fueron enterrados en aquel lugar. El interrogatorio de los vivos -entre ellos, el Alcalde, el Médico y los vecinos de diferentes edades- no tiene éxito. Lo único que consigue es revelar que nadie sabe nada: al parecer, en aquel pueblo no hubo ninguna muerte durante la guerra. Las preguntas del Hombre chocan contra un muro de silencio al tiempo que despiertan los recelos de algunos vecinos.

En escenas paralelas, Cavallé da entrada, presencia y voz, a los espectros de los miembros de la familia asesinada: el Abuelo, el Padre, la Madre, el Hijo y la Hija que, poco a poco, nos van contando su historia y su trágica muerte. Es decir, nos encontramos en un mismo espacio articulado en dos niveles diferentes: el mundo de los vivos y el de los muertos. Los primeros viven en el pueblo, los segundos están presentes en el espacio donde sus restos han sido localizados, atrapados en el momento del asesinato.

Después de varias escenas, por un lado, descubrimos que los viejos del pueblo conocían perfectamente los brutales acontecimientos, pero dado que la infame matanza sucedió en los días finales de la guerra y que las víctimas no eran del pueblo, sino una familia de otra localidad, hicieron como si nada hubiera pasado, guardando una especie de pacto de silencio colectivo. Por otro lado, de la narración de los muertos conocemos también la violencia ejercida por los soldados, ebrios de victoria, sobre cada uno de los miembros de esta familia. Incluso sabemos que el lugar donde fueron asesinados era un frecuentado lugar de recreo y romería de la gente del pueblo, un espacio comunitario pero misteriosamente olvidado desde el final de la guerra. El silencio sobre el secreto que guardaba aquel lugar convierte en cómplices a todos los vecinos del pueblo. Al fin, el Hombre de setenta años, antiguo compañero de clase de la niña asesinada identifica a las víctimas y trae una fotografía de la familia. El ayuntamiento celebra un entierro digno y

\footnotetext{
19 Simboliza toda España.

20 Originalmente, la obra fue escrita en catalán, pero se publicó también en castellano, en traducción del autor.
}

BEOIBERÍSTICA Vol. I / Número 1 (2017) | 133-146 
de reparación, con una lápida donde figuran los nombres de todas las víctimas y el Hombre de setenta años coloca en el monumento una fotografía que da rostro a los muertos. Desde este momento, los fantasmas -recuperando memoria, identidad y dignidad- pueden ya descansar. Y, para la comunidad, el trauma queda superado con el acto de duelo y reparación y con la desaparición de los espectros (Sansano 2014: 14-16).

Hay que destacar que Joan Cavallé no hace ninguna referencia a la guerra civil española, sino a "la guerra", a unos soldados, sin ningún distintivo específico y, de esta manera, el drama consigue un significado universal: puede referirse a cualquier acto de violencia de cualquier conflicto bélico. Gallén opina con razón que Cavallé quiere usituar su historia en un escenario universal, mítico" (2011: 21) a través de la figura de El Hombre de todos los tiempos, un personaje con función de mediador que actúa como un maestro de ceremonia y espectador privilegiado de la historia. Después de observar y escuchar todo, El Hombre de todos los tiempos llega a la conclusión de que la historia siempre se repite y el asesinato de las cinco víctimas fue otro episodio en la cadena de la barbaridad humana de todos los tiempos. Y aunque el trauma de la guerra civil española está en el fondo de la pieza, con los personajes anónimos -indicados solo con nombres comunes- y el espacio indefinido, el dramaturgo catalán acentúa que lo que ocurrió puede ocurrir en cualquier lugar y en cualquier momento:

Nada nuevo; ni incluso la execrable sevicia que se cebaba, cruel, sobre las pobres víctimas, aquí como en Nanking, o Troya o Srebrenica. Mirando a Hiroshima, lo de aquí es bagatela. Al saber de Mauthausen, la fosa adreatina o el bombardeo innoble de Dresde o de Gernika, sentimos gran alivio: sólo cinco cadáveres. [...] Bajo el sol, nada nuevo, si piensas en ello (Cavallé 2011: 79-80).

- nos recuerda El Hombre de todos los tiempos, dando una dimensión más amplia a la historia.

Las víctimas del drama de Cavallé -representantes de tres generaciones de una misma familia - formaban parte de una sociedad que debe asumir la reparación de la memoria colectiva. El silencio o la voluntad de ignorar unos hechos escalofriantes crean una conexión de culpabilidad entre los miembros de la comunidad. Este peso, con el paso del tiempo, se convierte en una sombra traumática que se proyecta sobre las nuevas generaciones, totalmente ajenas a los hechos acaecidos en el pasado. Para evitar esta situación, la sociedad tiene que asumir plenamente la historia colectiva con la identificación y reparación de la memoria de las víctimas. Son las nuevas generaciones que, con su actitud de respeto y reconocimiento hacia los desaparecidos, conjuran los fantasmas y ayudan a cauterizar las viejas heridas (Sansano 2014: 18). El tratamiento dramatúrgico de Cavallé multiplica las perspectivas sobre el valor de la memoria, combina lo transcendente y lo grotesco y alterna también lo factual y lo simbólico, la historia y el mito para activar los interrogantes sobre el pasado y para construir, sin olvidar los hechos, una memoria justa y reparadora (Francesc Foguet i Boreu 2009: 5). 


\section{A modo de conclusión}

Los dramaturgos, en las obras examinadas, abren la escena al acontecimiento histórico más importante del siglo XX de la historia española, la herida colectiva más viva y determinante para la sociedad española aún en el siglo XXI: la guerra civil. Todas las obras analizadas eligen un segmento del pasado que no deja de lanzar preguntas incómodas sobre el presente.

El silenciamiento de las tragedias del pasado para facilitar la reconciliación colectiva no puede implicar amnesia. "No vamos a guardar silencio, porque tenemos memoria" - escribe Juan Mayorga (2006: 60) resumiendo perfectamente la actitud de todos los dramaturgos que, en su teatro, asumen la responsabilidad de hablar en lugar de las víctimas.

La complicidad y la responsabilidad del silencio persiguen, como hemos visto, tanto a Ricken (en El triángulo azul) como a los vecinos de un pequeño pueblo catalán (en Pies descalzos...). El fotógrafo alemán, al no encontrar absolución, se suicida, mientras que la colectividad asume y reconoce públicamente sus pecados, su vergüenza y su actitud pasiva ante la crueldad (Gallén 2011: 21).

A modo de conclusión planteamos las siguientes preguntas: ¿Por qué eligen los dramaturgos citados un fragmento del pasado reciente de España? ¿Por qué excavan las fosas del silencio? Quizás, la mejor respuesta nos la da uno de ellos, Alberto Conejero: para que el recuerdo de todos los que sufrieron la guerra civil y la dictadura franquista no se borre de la mente de las generaciones futuras, "para que su memoria perdure" (Conejero 2015a: 4). Porque la memoria "no es una deuda con nuestro pasado sino con nuestro futuro" (Conejero 2015b: 9).

\section{BIBLIOGRAFÍA}

Aznar Soler, Manuel. “Teatro, política y memoria en El jardín quemado, de Juan Mayorga”. Anales de la literatura española contemporánea, Vol. 31, Núm. 2 (2006): 79-118. Impreso.

Becerra, David. "La Guerra Civil como moda literaria: Cazarabet conversa con David Becerra". Nueva Tribuna, 8 de abril de 2015. Web. 22 Nov. 2016.

Bertrand de Muñoz, Maryse. “Bibliografía de la creación literaria sobre la Guerra Civil Española». ALEC, 11 (1986): 357-411. Impreso.

Cattaneo, María Teresa. "En torno a cincuenta años de teatro histórico". Boletín Informativo de la Fundación Juan March, 188 (1989): 3-14. Impreso.

Cavallé, Joan. Pies descalzos bajo la luna de agosto. Tarragona: Arola Editors, 2011. Impreso. 
Colmeiro, José. "Memoria histórica e identidad cultural. Del cuarto de atrás a la primera plana". Revista de Estudios Hispánicos, XXXV, 1 (2001): 151-163. Impreso.

Conejero, Alberto. "Notas del autor a La piedra oscura". Dossier de prensa de "La piedra oscura”. 2015a. Web. 4 Dic. 2016.

-. "Entrevista con el autor", La piedra oscura de Alberto Conejero. Cuadernos Pedagógicos, 74 (2015b): 7-10. Web. 4 Dic. 2016.

-. La piedra oscura. Madrid: Antigona, 2015c. Impreso.

Floeck, Wilfried. "Del drama histórico al teatro de la memoria. Lucha contra el olvido y búsqueda de identidad en el teatro español reciente». José Romera Castillo (ed.), Tendencias escénicas al inicio del siglo XXI, Madrid: Visor, 2006: 185-209. Impreso.

Foguet i Boreu, Francesc. "Memòria d'un ignominia". El País, 4-06-2009, 5. Impreso.

Fox, Manuela. "El recuerdo de la dictadura franquista en Bagaje de Jerónimo Lopez Mozo: un ejemplo de teatro metamnemónico". Silvia Monti, Paola Bellomi (eds.), Scene de vita. L'impegno civile nel teatro spagnolo contemporaneo, Alessandria: Edizone dell'Orso, 2012: 109-120. Impreso.

Gallén, Enric. “Prólogo". Pies descalzos bajo la luna de agosto de Joan Cavallé. Tarragona: Arola Editors, 2011: 7-21. Impreso.

García Martínez, Anabel. El telón de la memoria: La Guerra Civil y el franquismo en el teatro español actual. Hildesheim: Georg Olms Verlag, 2016. Impreso.

Gibson, lan. "Introducción al drama La piedra oscura". Centro Dramático Nacional. Web. 4 Dic. 2016.

Guzmán, Alison. "La memoria de la Guerra Civil en el teatro español: 1939-2009". Tesis doctoral, 2012. Web. 22 Nov. 2016.

Henríquez, José. "Entrevista con Laila Ripoll. "Soy nieta de exiliados y eso marca" . Primer Acto, 310 (2005): 118-129. Impreso.

Hirsch, Marianne. Family Frames: Photography, Narratives and Postmemory. Cambridge: Harvard University Press, 1997. Print.

Huyssen, Andreas. Twilight Memories: Marking Time in a Culture of Amnesia. New York; London: Routledge, 1995. Print.

Llorente, Mariano - Ripoll, Laila. El triángulo azul, Madrid: Centro Dramático Nacional, 2014. Impreso.

Mayorga, Juan. "El teatro es un arte político. Manifiesto alternativo escrito por Juan Mayorga y leído el 27 de marzo de 2003", citado al final del artículo de Mariano de Paco, "Juan Mayorga: Teatro, historia y compromiso". Monteagudo, 11 (2006): 59-60. Web. 4 Dic. 2016.

—. El jardín quemado. Juan Mayorga: Teatro 1989-2014. Segovia: La uÑa RoTa, 2014. Impreso.

Monleón, José. “Himmelweg, de Juan Mayorga. La construcción de la memoria». Primer Acto, 305 (2004): 25-27. Impreso. 
Ripoll, Laila. El convoy de los 927. Manuscrito concedido por la autora, 2007. Impreso.

- Trilogía de la memoria: Atra bilis, Los ñiños perdidos, Santa Perpetua. Bilbao: Artezblai, 2013. Impreso.

Sansano, Gabriel. "De fosses i fantasmes. Memòria, trauma i identitat en l'escena catalana actual». Journal of Catalan Studies, 2014. 4-22. Imprès. 